\title{
LOCAL RESPONSES TO GLOBALIZATION: NEW OPPORTUNITIES FOR THE SAN DIEGO-TIJUANA REGION*
}

\author{
By \\ Norris Clement**
}

\begin{abstract}
This article examines the current economic, political, social and administrative situations of San Diego, with particular emphasis on the economic aspect, and on the interrelatedness of the two cities. Both cities currently find themselves in an ongoing economic decline. The article examines theoretical concepts for dealing with the problems of the region, and looks at some North American, as well as European, models which might provide useful information for the formulation and development of regional development strategies. Attention is given to the "demilitarization" of San Diego, and its effects on the local economy. Recognizing the special problems related to the international border, the article explores alternate development plans, and hypothesizes as to the outcome of each.
\end{abstract}

\section{RESUMEN}

En este artículo se examinan las condiciones políticas, sociales, administrativas y económicas de las ciudades de San Diego y Tijuana, haciendo énfasis en este último aspecto y en la interrelación entre ambas ciudades, mismas que actualmente se encuentran en paulatina decadencia económica. Se realiza además una revisión conceptual que permita abordar el estudio de la problemática de la región, así como un análisis comparativo tanto de modelos norteamericanos como europeos, que puedan proveer información útil para implementar estrategias de desarrolloregional. Se toca también el tema de la "desmilitarización" de San Diego, y sus efectos en la economía local. Por último, se proponen planes alternativos de desarrollo para la zona, tomando en cuenta los problemas relacionados con la frontera internacional, y se plantean hipótesis del posible resultado de cada uno de estos planes.

San Diego, like many other cities in the developed world, is now going through a painful process of economic, political, social and administrative restructuring. This process comes in response to a convergence of longterm changes in the economic structure (i.e., increased internationalization

\footnotetext{
* Article presented at The New International Cities Era (NICE) Conference "North American Cities and the Global Economy: Challenges and Opportunities".

** Department of Economics, San Diego State University.
} 
and competition, cuts in military-related expenditures and other fiscal constraints generated by huge-budget deficits), as well as short-term, cyclical factors (i.e., a weak recovery in the U.S., hindered by recessionary conditions in the world's main industrial economies) (Gerber, 1993).

Viewing San Diego's situation -its current problems and its potential for future development - within this context, however, could lead to incorrect policy recommendations. It has been argued elsewhere (Clement and Zepeda, 1993) that historically, San Diego's economic base and public policy vis-a-vis infrastructure and economic development have been unusually dependent on external forces (i.e., defense-related expenditures and the strong presence of the military). Thus, San Diego cannot be viewed as simply another once-booming, industrial city in decline, retooling for the 21st Century. In fact, this may be the first time, at least in this century, that San Diego has had to take full responsibility for its own economic future.

Tijuana's once rapidly-expanding economy has also slowed considerably in recent years, and due to a combination of national and international factors, real per capita income is now declining. Additionally, infrastructure development has not kept up with economic and population expansion and, as the heavy rains of early 1993 dramatically demonstrated, future economic development may be limited if the situation is not remedied (Clement and Zepeda, 1993).

In response to these crises, important public and private entities in both cities have initiated an intense, on-going discussion regarding the region's future. Most leaders on both sides of the border have now come to recognize that to improve the region's competitiveness, living standards and quality of life, the two cities must quickly mobilize their resources in order to formulate and implement aggressive economic development strategies.

This paper attempts to enhance that discussion. It summarizes the main findings of a two-year project carried out by the author, the purpose of the project was to understand better the responses of other city-regions in North America and Europe to the new conditions presented by globalization and increased economic integration, and to apply those findings to the local region. ${ }^{1}$ It is hoped that the ideas presented here will

1 The hypothesis guiding the project's development was: Given the structural economic changes enumerated above, and San Diego's unique location with respect to Tijuana specifically, and Mexico, Latin America and the Pacific Rim generally, its economic future lies in: a) correctly identifying San Diego's current and potential function(s) in the global. 
stimulate new ways of thinking among local researchers, politicians, and public and private officials as they attempt to respond to the current crisis-situation facing the San Diego-Tijuana region. The author's perspective, however, is distinctly a San Diego one.

The first section of this paper synthesizes the main elements of recent thinking in the area of regional development, in the context of the increasingly internationalized economic environment. The main point is that over the last three decades, technological innovations have forced dramatic changes in the organizational structures of manufacturing and service firms, as well as how and where they conduct business. These changes have led to important developments in the spatial distribution of both economic activity and employment patterns which, in turn, require governments at all levels to reassess their organizational structures and the functions they provide. The main impact of these changes has been to increase the responsibility of city and regional governments in providing for local economic development. ${ }^{2}$

The second section outlines recent institutional responses to the increasingly internationalized, "borderless" environment in which these new responsibilities are being assumed. The main concept here is that certain types of cooperation (i.e., alliances, networks and partnerships) can increase the efficiency of both governments and private firms and, in turn, enhance the competitiveness of the region.

economy, as well as those industries and clusters of industries capable of generating highpaying employment opportunities for the region's rapidly-growing work force, and b) developing new private public mechanisms for organizing the use of the region's ample resources more efficiently. The project was initiated early in 1992, and continued throughout the summer of 1993. Travel was supported by grants from the Center for International Business Education and Research (CIBER), and the Canadian government. The first (and ongoing) phase of the project was to survey the existing literature in this area, while the second was to visit several cities clustered around the United States-Canadian border during the summer of 1992, and in Europe during the summer of 1993. The object of this series of visits to meet with researchers, and public and private officials involved in the formulation and/or implementation of the various concepts spelled out below.

he author is deeply grateful to colleagues involved in similar research in the NICE ("New International Cities Era") project (see Fry, E., Radebaugh, L. \& Soldatos, P., 1989), whose work provides both a theoretical and empirical base for this type of work, as well as a growing global network of researchers and practitioners. Additionally, the author would like to acknowledge the research assistance provided by Teresa Cisneros Donahue and Domink Tschirky, two international business students at SDSU, and also the critiques provided by SDSU colleagues and associates on the Strategies Trade Alliance of the San Diego Region (STAR).

2 Throughout this paper the terms city and region will be used interchangeably. It is understood that in each "region", however defined, there is a leading city and a "hinterland", as well as smaller cities. The identity of the region, however, is usually defined by the use of the leading city's name (e.g., the City of San Diego in the San Diego Region). 
The final section of the paper focuses on the potential application of these concepts to the U.S.-Mexican border region generally, and the San Diego-Tijuana region specifically. The distinguishing feature of "border cities" is that, in addition to the usual array of economic, political and administrative problems involved in the formulation and implementation of regional development strategies, there are additional problems, due to the presence of an international border.

\section{BACKGROUND/CONTEXTUAL ISSUES: A PARADIGM SHIFT?}

This section presents the main intellectual components of a "paradigm shift8 regarding the new role of cities-regions in today's increasingly globalized economic environment. ${ }^{3}$ Frames I-IV summarize the four levels of change, moving from technological changes (I) to the effects on economic structures (II), which in turn affect the changing spatial distribution of industry (III) and changing government structures and functions (IV).

In Frame (I) the main motor of change is identified as technological change, primarily in the transportation and communications sectors, but also in the information/computer sectors. Not only have these key services become cheaper, they also have become faster and more widely available throughout the world. Thus, many firms are now freer to "go international", to locate (geographically) any or all phases of production wherever costs are lowest or conditions most appropriate to the firm's overall strategy.

"Smart firms" are now able to devise global strategies and decentralize and/or disperse their operations, and thereby manage from afar through fax, voice and data transmission, while shipping components and products via transportation systems which each day become cheaper and offer more options. The resulting spatial redeployment of production, along with the tendency toward trade liberalization carried out under the auspices of multilateral institutions such as GATT (General Agreement on Tariffs and Trade), and the formation of regional trade blocs such as the EC (European Community) and the cusfTA (Canada-United States Free Trade

3 The term "globalization" simply means that relatively more economic transaction, of all types, takes place across international borders. Thus, for example, production of manufactured products today frequently involves the use of components produced in many countries, while financial capital (i.e., stocks, bonds, loans) flows to wherever returns (discounted for risk) are the highest. Globalization has increased in recent decades because, as we shall see below, technological innovation has made it easier and cheaper, and because prolectionism has diminished. 
Agreement), and the emergence of many Third World countries as major manufacturing powers, has dramatically increased global competition. But, as we will see below, the accelerated pace and cost of technological innovation has also increased cooperation as well.

\section{Table 1. The Change Process: Dominant Features (Technological Innovation).}

\begin{tabular}{ccc}
\hline $\begin{array}{c}\text { transportation costs } \\
\text { (information) } \\
\text { communications costs }\end{array}$ & $\begin{array}{c}\text { Globalization } \\
\text { (prod/dist) } \\
\text { decentralization } \\
\text { (geographical dispersal) }\end{array}$ & $\begin{array}{c}\text { competition } \\
(+) \\
\text { cooperation }\end{array}$ \\
\hline
\end{tabular}

Frame II outlines the main changes in economic structure in recent decades. (The shift from "old/traditional" structures and institutions to "new/emerging" ones reads from left to right).

What is well known, is the transformation of production in all developed economies, although in varying degrees, from the "real goods" sectors (agriculture and manufacturing) to service and information-based economies. The shift from large, to small and medium-sized firms as the main source fo new jobs, is also well- documented, as is the shift from a regional/national perspective to an international one (i.e., sourcing inputs "offshore" and marketing outputs globally). What is not so well known, however, is that enormous changes are taking place within firms, especially high-tech companies, changes which include:

- The emergence of computer-aided technologies which permit manufacturing firms to efficiently produce small quantities of "custom made" products. Such flexible production systems respond to the "economies of scope" instead of the "economies of scale" associated with traditional, large manufacturing firms. ${ }^{4}$

- The gradual demise of traditional assembly lines and hierarchical organizational structures with a reliance on highly- skilled and experienced workers.

- More use of outside technical and business service, together with increased use of subcontractors, blurring the traditional distinction between manufacturing and services, while creating new kinds of industrial "clusters."

4 The concept of "economies of scope" refers to production processes that respond to meeting a more varied demand with shorter production runs, and "is characterized by flexible production methods and the ability to alter product and process specifications rapidly" (Commission of the European Communities, 1991:53). 
While these new practices often result in lower costs and an enhanced ability to respond to new market opportunities, employees' work roles and traditional notions of job security are changing considerably, increasing the need for worker retraining, counseling and relocation-services usually provided by government.

Finally, note that firms no longer are exclusively competitive. The need to innovate rapidly, and the enormous costs of developing new products and techniques have pushed firms into cooperative networks and alliances with competing firms, governments and university research centers (Reich, 1992).

Table 2. Economic Structures (how firms organize \& do business).

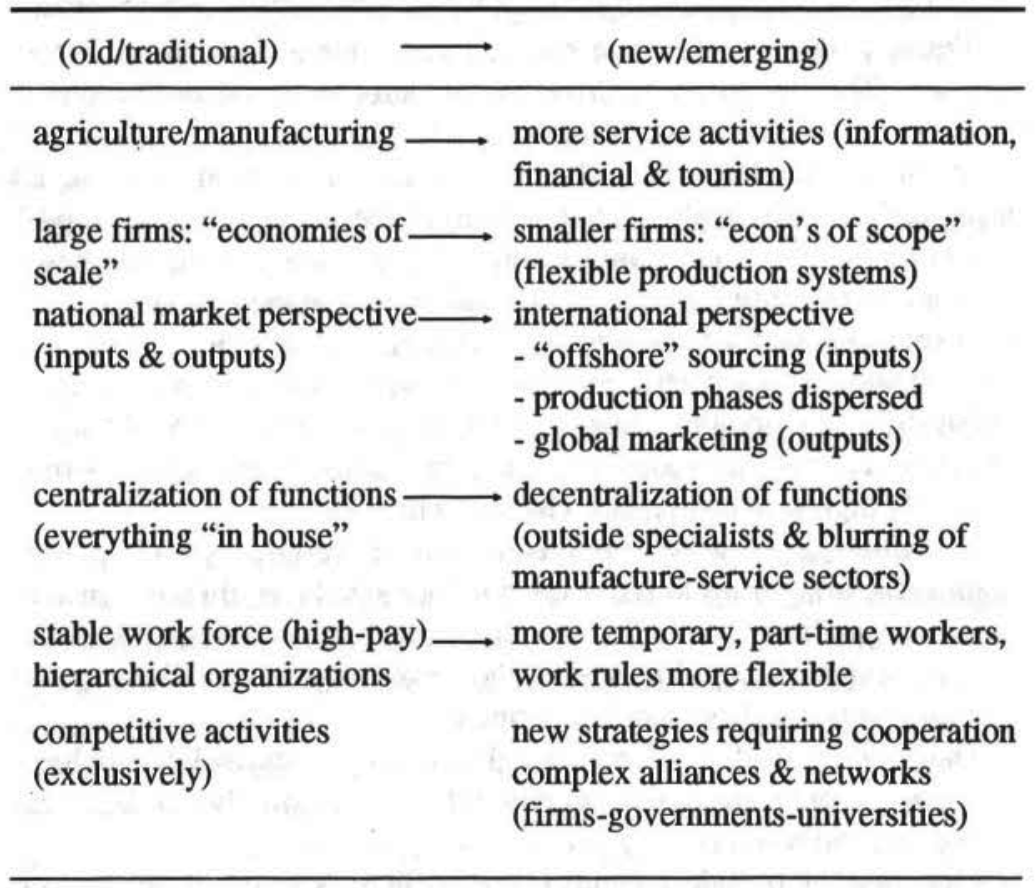

Frame III summarizes the effects of these changes on the regional (geographical) structure, or location of industry: the spatial dimension of the story. Traditionally, regional structures have been viewed in a dichotomous framework of "core-periphery". Traditional core areas -formed on the bases of proximity to resources, suppliers, and markets- were characterized mainly by large-scale manufacturing 
firms involved in the production of producer goods and consumer durables, as well as large financial firms. Meanwhile, activities like agriculture, forestry, fishing, mining and small-scale manufacturing activities were located in the periphery.

Now, however, it is clear that since industrial restructuring began in both the U.S. and Europe in the 1970's, traditional core areas have been transformed in terms of both production techniques and product types (i.e., most mature products have either been automated or moved to lower cost regions), and a "new core" has emerged, mainly in southem states. Simplistically, new core areas are characterized by all of the characteristics of the modern firm, as portrayed in the previous frame. What is important here, is that these firms seek different location characteristics which, within some limits, emphasize qualitative aspects (e.g., climate and environment) over quantitative cost factors. And, in the new scheme of things -disappearing economic borders- the cul-de-sac quality of border cities diminishes, presenting many new opportunities...if they are able to negotiate collaborative relationships with their neighbors "on the other side.

Frame IV outlines the major changes in governmental structures and functions that have come mainly in response to the changes already presented in frames I-III.

- At the national level, stabilization measures, monetary and fiscal policies, traditionally used to combat the extremes of the business cycle, have become less effective in the 1990 's due to a) increased globalization, resulting in fewer degrees of freedom, b) large budget deficits that make stimulatory policies politically unacceptable, and c) a growing awareness that economic problems in the U.S. and Europe are structural, not cyclical.

- Growing dissatisfaction with statist policies (industrial policies) has resulted in more selective uses of government; however, the U.S. may just be "catching up" in this regard.

5 What is not clear, is the effect of changing technologies on income differences between regions. In the U.S., regional differences in per capita personal income growth narrowed in the period 1929-1979, but since 1979 have widened, due to many factors, including technological change. (Garnick, 1990). However, in Europe, in spite of considerable economic development and ten years of regional economic development programs, "no fundamental change could be realized in regional disparities" (Atalik, 1990:11).

In theory there are two possible outcomes: the two-stage "Williamson hypothesis (increasing regional income inequality in the first stage of a country's development, followed by increasing equality in later stages), and the so-called "typhoon principle", which posits that the effects of any external force on a multi-regional economy will tend to make the richer regions better off, and the poor ones worse off" (Nukamp, 1990:3).

At a more practical level, it appears that the cities/regions that actively respond effectively to the conditions are those that actively and effectively respond to these changing conditions. 
Table 3. Regional Structure (reflects changing location determinants).

\begin{tabular}{ll}
\hline (old/traditional) & (new/emerging) \\
\hline $\begin{array}{l}\text { core-periphery: dynamic } \\
\text { industries in core }\end{array}$ & $\begin{array}{l}\text { "old core" (restructured, diverse) } \\
\text { "new core" (smaller, niche mkt's) } \\
\text { "periphery" (most other regions) }\end{array}$ \\
$\begin{array}{l}\text { location factors (costs: } \\
\text { proximity to resources, } \\
\text { markets \& suppliers) }\end{array}$ & $\begin{array}{l}\text { congestion costs in "core" rise } \\
\text { mature industries low-wage areas } \\
\text { new industries - climate, QOL labor } \\
\text { force, research facilities }\end{array}$ \\
border regions in periphery $\longrightarrow \begin{array}{l}\text { new core(?): new opportunities } \\
\text { available, but not guaranteed }\end{array}$ \\
\hline
\end{tabular}

- Restructuring frequently is "good for the economy, bad for the people", at least in the short run, resulting in growing demand for government services and/or transfer payments. The attack on "welfare" has also meant an attack on immigrants in many countries.

- As national governments attempt to "reinvent government", new forms are tried, beginning with decentralization, expanding to "strategic urban networks", especially in the EC (see below).

- With new emphasis on high tech, high value-added activity and rising income gaps between regions, "smart (sub-national) governments" devise strategies to play the economic game better. These include developing new private-public academic partnerships while universities provide new functions and play new roles.

\section{EUROPEAN AND NORTH AMERICAN RESPONSES}

Before examining cities'responses to the new conditions facing advanced economies today, it may be helpful to restate those conditions in summary form.

In recent years both economic and job growth have slowed, due to an unfortunate convergence of structural and cyclical factors. In this regard, it may be helpful to view the decade of the 1990's as another "watershed decade", similar to the 1930's, marking the end of the Post World War II period. In this context, traditional macroeconomic stabilization and structural change policies at the national level are either ineffective or inappropriate in 
Table 4. Governmental Structures and Functions (responses to the above).

\begin{tabular}{|c|c|c|}
\hline (old/traditional) & $\longrightarrow$ & (new/emerging) \\
\hline $\begin{array}{l}\text { stabilization policies: } \\
\text { monetary/fiscal }\end{array}$ & $\longrightarrow$ & $\begin{array}{l}\text { less national autonomy due to } \\
\text { globalization, budget deficits }\end{array}$ \\
\hline $\begin{array}{l}\text { industrial policies } \\
\text { (national level) }\end{array}$ & $\longrightarrow$ & $\begin{array}{l}\text { [in US] now expanding at } \\
\text { national \& regional levels } \\
\text { [in EC] subordinated to regional } \\
\text { policies shaped in Brussels }\end{array}$ \\
\hline social welfare system & $\longrightarrow$ & $\begin{array}{l}\text { under attack everywhere as } \\
\text { unemployment \& costs grow } \\
\text { (immigrant role here important) }\end{array}$ \\
\hline $\begin{array}{l}\text { large, centralized } \\
\text { (national level) }\end{array}$ & (EC) & $\begin{array}{l}\text { decentralized: to local/regional } \\
\text { "smart" govt. "reinventing" } \\
(+) \text { transnational (EC) } \\
\text { (+) int. borders disappear } \\
(+) \text { networks (Eurocities) }\end{array}$ \\
\hline $\begin{array}{l}\text { universities: national } \\
\text { governments support educ } \\
\text { tion \& basic research }\end{array}$ & & $\begin{array}{l}\mathrm{R} \& \mathrm{D} / \text { training functions at } \\
\text { regional level increase as do } \\
\text { alliances with firms/governments } \\
\text { (pvt.-pub,-academic partnerships) }\end{array}$ \\
\hline
\end{tabular}

dealing with the increasingly globalized environment, where economic change is accelerated due to rapid technological innovation.

In response to rapid technological change and increased competition from low wage countries, firms have experienced a dramatic evolution in both structure and organization. Technological change has made it possible to operate on a global level, with location of operations not tied exclusively to traditional cost considerations. In fact, for many firms, profits and market share depend more on rapid product development than simple cost reduction. Thus, it is increasingly important to locate in, or create a milieux that supports innovation. ${ }^{6}$

6 In 1985, there was founded in Paris an international group of scholars called GREMI (Groupe de Recherche Europeen sur les Milieux Innovateurs), which is engaged in the study of technological innovation processes and policies at the regional and local level. For an example of recent GREM publications, see, Philippe Aydalot and David Keedle (1988), 
Thewe and many other factors have resulted in different spatial patterns of economic mitivity. The traditional core-periphery distribution has hecome more variegated, providing new economic opportunities for morker localitics that previously found themselves condemned to the periphery (i.e., enlarged hinterlands and new prospects for attracting investment).

Meanwhile, many cities and states are mired in budget crises and a downward spiral of service cuts and tax increases. In this context, most cities/regions and states in the U.S. have responded by expanding their economic development efforts, mainly by:

a) attempting to quickly "improve the local business climate" by reducing regulation, bureaucracy and taxation,

b) expanding "city marketing" efforts by encouraging local producers to expand exports, and by attracting outside firms to locate and/or invest in their area.

This dual response is primarily a competitive one, and frequently results in "bidding wars" where, in exchange for jobs and investment, localities vie to provide the best package of incentives to prospective firms.

There are, however, other longer term, cooperative policies which are now being employed in Europe and, to a lesser extent, in North America. Some of them could easily be adapted to the needs of U.S.-Mexican border "twin cities" such as San Diego-Tijuana.

Urban Networking. This cooperative approach recognizes that while cities must compete in some areas (e.g., in attracting visible events like the Olympic games or in attracting investment), each city can increase its own competitivenesss by cooperating with others in many other areas (e.g., exchanging information on programs to combat common urban problems, or lobbying together for needed urban policies at the national or transnational level). ${ }^{8}$

Urban networking has taken many forms and has been embraced enthusiastically by academics, and public and private officials and practitioners (Ekistics, 1991-92). It is easy to see why: local officials in various cities working together to change or expand EC urban policies, or

7 One study estimates the cost of incentive packages provided by local governments vying for new automobile plants in Midwestem U.S. cities in the period 1978-90, at $\$ 3900$ to $\$ 108000$ per job (Glickman and Woodward, 1989).

Urban networking is not unknown in the U.S. or Canada; both countries have associations which exchange information, and lobby on behalf of urban interests. Nevertheless, both the scale of the effort, and the emphasis on the internationalization of cities seems to far outweigh anything that now exists in North America. However, an organization called, "North America Cities International", was proposed at a "founders conference" at Wingspread Conference Center, in April, 1992, by a group of involved in the NICE Project noted above. 
to resolve trans-jurisdictional problems across borders, or exchanging information on "best practice" programs to resolve common urban problems, can both improve the efficiency of local government and increase the competitiveness of private firms in the region. Several programs are worth presenting here,

\section{European Cooperation Networks}

This program, introduced by the EC in 1991, provides supplemental financial support to some 37 networks, in order to promote the economic performance of less-favored regions by transferring technology and expertise. The areas covered include economic development, planning, transportation, environment, tourism, education and training, emergency relief service, etc. The networks are based on a wide variety of themes, ranging from "Demilitarized" and "Environet", to "Euroisles" and "Universities-Regions", Of these networks, one which has attracted attention in North America is "Eurocities", which was established in 1986 as a forum for European "second cities", and now has a membership of more than 40 large cities throughout Europe. The Eurocities network, which has received co-funding from the EC for certain sub- projects, carries out three types of activities:

- "experience transfer" (e.g. "best practice" in the area of economic promotion),

- lobbying in the EC context (e.g., for the development of an effective EC urban policy), and

- project development in the areas of transportation and communications infrastructure involving more than one city (e.g., the development of a high-speed rail line between Lyon and Turin).

Apparently, the Eurocities network has been very successful, so much so that its large membership has made policy formulation and implementation increasingly difficult. In response, another cities network, "Eurometropoles", has emerged with a more focused mission and a smaller membership. $^{10}$

\footnotetext{
9 Information packets on each of these programs is available in from the Directorate-General for Regional Policies (DG XVI) in the Commission of the European Communities in Brussels. The program summaries presented here were taken from that information, and, from interview with De. Marios Camhis, head of division in July, 1993.

10 "Eurometropoles" was established on 1990 with a smaller membership (about 20 cities), and a focus on promoting economic development through agglomeration policies involving closer relations between local governments, private firms and universities. Much of the information presented here on Eurocities and Eurometropoles was provided in an interview with Pierre Yves Tess of the Chamber of Commerce and Industry of Lyon, in July, 1993.
} 


\section{Urban Pilot Projects}

While the needs of cities seem to be unlimited, EC resources are not. Thus, because it cannot and should not do everything -in agreement with the EC's "principle of subsidiarity" (i.e., that each higher level of government should do only what lower levels cannot do for themselves) - the Community recently began to fund pilot projects designed to test concepts for improving the effectiveness of urban policy in three problem areas:

- lack of access to jobs and training by people who live in peripheral and inner-city neighborhoods,

- increasing economic prosperity, while preserving the environment, and

- revitalizing economic life in historic city centers.

The results of the projects will then be disseminated to cities and member-country governments, and utilized in the formulation of local, national and $\mathrm{EC}$ policies.

\section{Cross-border Cooperation}

European border regions vary a great deal with respect to population density and economic development, but all tend to suffer from certain "handicaps". These include: lower incomes and higher unemployment rates in their own national context, a peripheral position with respect to national economic and political decision-making and the problems imposed by the propinquiy of different legal and administrative systems, poor cross-border communications, and a lack of coordination in public services, as well as differences in culture and language.

In the context of the EC's push towards a "single market," borders are losing much of their historical significance, but the transition to a borderless economy will take some time. Thus, in 1990, the EC launched a special border program, INTERREG, to promote cross-border cooperation for economic development.

It is important to note that the $\mathrm{EC}$, as a common market, has both "internal borders" (i.e., borders between member countries, like France and Germany) and "extemal borders" (i.e., borders between member and non-member countries, like Germany and Poland). The economic differences between member countries are much less than between member and non-member countries.

The creation of the single market is expected to improve the position of regions on internal borders, but may create unfavorable conditions for those on the external borders as they move from the periphery of a national 
market to the periphery of the much larger EC market. Additionally, the borders of the former Soviet Bloc countries were essentially sealed until just a few years ago, and cross-border cooperation was virtually nonexistent. Nevertheless, the INTERREG program is designed to help both types of border regions to better confront the opportunities and challenges presented by increasing economic integration.

One of the most interesting and complex border regions in Europe is situated at the intersection of Switzerland, France and Germany. The "Regio", which was founded on the Swiss side in 1963, is based upon strong cultural ties, including a common history, language, literature, folklore and architecture. After thirty years of collaborative activity, there are now on-going projects in economic development, transportation infrastructure, environment and energy, as well as culture and media/communication, that involve the governments at all levels, along with private firms and universities (Regio Basiliensis, 1988).

City Strategies. Every city-region wants economic prosperity and a high quality of life. The problem is that both objectives are becoming more and more elusive. As noted above, it is no longer acceptable for national governments to simply "prime the pump" with deficit spending to solve a nation's economic ills. Increasingly, cities must depend on their own resources for solutions.

Most people in developed countries now live and work in cities. Thus, if a nation is to be competitive, its cities must be competitive. Similarly, if a city is livable and competitive, it is because local decision-makers, working together and with others outside the region, make it happen.

The question is, how does a city in decline pull itself up by the bootstraps in this new environment? Simplistic answers to this question abound: create a friendly business environment; provide incentives to attract new firms and retain existing ones; expand exports; internationalize.

Unfortunately, none of these alone are likely to provide a large, economically-diversified city with adequate levels of prosperity and quality of life $(\mathrm{QoL})$. In fact, some of these proposed solutions could raise one and lower the other, or in the long term, reduce both. What most cities are after these days is increasingly referred to as "sustainable

\footnotetext{
II A recent report (Martinos and Caspari, 1990) summarizes the results of an EC-commissioned, two-part study on cross- cooperation in Europe. "Part I reports on the problems and initiatives in border regions", "while Part II 'develops' characteristics, border a strategic approach to cross-border cooperation, and makes a number of suggestions concerning the types of action and institutional arrangements..." (Martinos and Caspari, 1990:2). This brief report ( $84 \mathrm{pp}$.) provides an excellent basis for analyzing border situations and developing cooperative strategies useful for academics, practitioners and decision-makers in border regions throughout the world.
} 
development", although this concept has not yet been made operational at the local level. ${ }^{12}$ Nevertheless, as we shall see, for most cities in the developed world a high QoL (a "city that works", both for business and for the people who live there) has become a necessary, and perhaps even a sufficient condition for achieving economic prosperity.

The response of many cities in this situation has been to initiate a process leading to a "city strategy". Usually, four steps are involved: analysis, formulation, implementation and evaluation - all of which draw upon the specialized talents of individuals and institutions in the region and can be openly discussed, so that the process is transparent and the strategy itself receives wide public acceptance. ${ }^{13}$ This process, drawing upon the specialized knowledge of individuals from business, labor,government and academia, can be organized in a variety of ways, but must be approached as a long-term, multi-year project, leading to fundamental changes in public policy,

\section{Phase \#1. Analysis}

Analysis means research carried out in collaboration with a speciallyconstituted task force drawn from all sectors of the economy. The objective of the research is to determine, on the basis of the city's actual and potentially available resources, the city's basic function(s) in the global, national and regional economies, as well as to identify those industry sectors (and clusters of industries) that are likely to be the strongest in the medium and long term. In other words, what are the city's competitive advantages now, and what could they be in the future, with public support?

In this regard, Kresl's (1991) analysis of the concept of the "Gateway City" (i.e., location on a physical or man-made "border") is useful, especially the distinction be draws between:

\footnotetext{
12 See Nico Calavita's discussion of this issue with respect to San Diego and other U.S. cities in his article "Measuring 'Quality of Life' in San Diego", (Clement and Zepeda, 1993). The author's own operational definition of sustainable development is: "That level and composition of current output that is consistent with preserving the environment for the benefit of future generations". See also British Colombia Round Table on the Environment and the Economy, 1993, for an operational discussion of what this means for a particular region.

13 This section draws heavily on Peter Kresl's excellent book Peter Kresl (1992), which can be helpful to the reader interested in more detail on most of the subjects covered in this article. Kresl, however, refers to the four-step process outlined here as "Strategies for City Internationalization". While more "internationalization" must occur in most cities of any size, empirical analysis might reveal that San Diego's best actual and potential customers are in adjoining regions (e.g., Los Angeles and/or Tijuana).
} 
- "Bridge Cities" like Buffalo and Seville: "cities which serve as conduits between two economies". These require significant investments in physical infrastructure such as ports, highways and bridges.

- "Points Of Access Cities" like Montreal and Copenhagen: cities which serve "as a point from which economic actors may gain access to cities in the other country," These require "office space, housing for high-income individuals, urban cultural amenities such as museums, galleries, a concert hall, recreation facilities and parks, and a good educational system" to attract business and financial services companies.

With respect to the types of firms that a city-region can expect to attract (and/or retain), there are two views. The first one maintains:

"The competitive position of regions is largely determined by comparative cost advantages, technological progress, agglomeration economies, and the creation of a specialized market niche" (Nukamp, 1990:4).

Traditionally, this has meant that firms, especially high-tech firms, locate in those regions where costs are reasonable, and other conditions are appropriate to creating an "innovative milieu" vis-a-vis specific product lines (e.g., bio-med or bio-tech). The other view, however, assigns more important to QoL factors.

According to a new (EC) study, firms are influenced by a wide range of location factors in deciding where to invest, and the factors which are of most importance vary considerably between projects. In general, location factors fall into three groups: market-related factors (access to EC market, strong national market, proximity to major customers and suppliers, general economic climate), the transport and communications infrastructure, and labor. When it comes to the final choice of location, qualitative factors appear to be more important than quantitative (cost-related) factors, firms being prepared to trade off cost disadvantages to secure qualitative advantages, such as a pleasant climate and a good general living environment (Commission of the European Communties, Directorate-General for Regional Policy, 1991:55).

Finally, the city strategy process should lead to a "map of the city's economic space" (i.e., determine the geographical locations of the region's most important trade, financial and technological partners). This information regarding existing relationships, together with information on expanding national and international market sectors, can be used to identify potentially competitive activities, and redirect public policy to foster emerging industry sectors. 


\section{Phase \#2. Formulation of a Plan}

At this point, the economic analysis must be synthesized and brought together to form a consistent and comprehensive plan for future actions. The basic question here is, what can public policy do to strengthen the current and potential competitive advantages of the region? Other questions to be answered include:

- Is additional infrastructure needed in order to attract new industries or retain existing ones? If so, how much will it cost, and how will it be financed? If there are competing uses for infrastructure dollars, which uses will yield the highest returns in terms of incomes, jobs and taxes for the region?

- Does the region have the necessary resources (i.e., water and energy) to support the emerging industry sectors in the future at reasonable costs? If not, what can be done?

- Are there regulations or laws that should be changed at the local or state level to increase the region's competitiveness without compromising the region's QoL?

- Given current trade patterns, what can be done to increase the region's exports and reduce its imports?

- Are incentives available that would stimulate local firms to expand their operations locally or attract new firms, without compromising the region's fiscal base?

- Given the region's cost structure, positive and negative attributes, and needs to create both diversity and industrial clusters, what types of firms should be targeted as being attracted to (or retained in) the local region?

- What kinds of educational/training policies are necessary to enhance the region's economy in the future?

- How can the region's universities and colleges be better utilized to support efforts to become more competitive, nationally and internationally?

- What kinds of actions can be taken to increase the city's image and presence in international markets?

- What steps can be taken to assure that the region's efforts to increase economic prosperity will be consistent with the need to achieve a high QoL?

- Is the city equipped to conduct its own national-international policy, with an office of protocol, an agency for managing sister-city relationships and related matters?

It should be clear from this short list of questions that there are many trade-offs to be confronted. Given the diminishing resources available to the public sector, priorities must be established and hard decisions made. 
However, isolated decision-making bodies are frequently oblivious to, or tend to ignore, the negative consequences of their actions on the general planning process. Thus, it is important that some sort of mechanism be created to impose consistency on the overall process. In this regard, collaboration between decision-making bodies is important, both horizontally (i.e., between groups dealing with different functional areas like infrastructure and city marketing) and vertically (i.e., between various levels of government). Ideally, the region should strive for a privatepublic-academic partnership, developing "positive synergies" that pay off in terms of both enhanced prosperity and QoL.

While each city's plan will be different, Table 1 provides a general outline of the main elements contained in a typical plan. The ideas in parentheses are meant only to be suggestive, not exhaustive.

\section{Table 5. Main Elements of a City Strategy.}

Overview of Current Competitive Position and Future Prospects

Strengths (city functions, strong sectors, location)

Weaknesses (transportation facilites)

Needs (infrastructure, complementary business services)

General Strategy (what will be done; who will do it; etc.)

Objectives: (should be well defined)

Economic (jobs created, firms retained/attracted)

QoL (highway congestion, educational system)

Action Components

Legislative (improving the general business environment)

Inter-governmental (developitg vertical-horizontal synergies)

Infrastructure

Physical (transportation, ports, communications)

Information (data sets, existing studies, accessibility)

Social (education/training, health care, social services)

Technology-Innovation (incubators, venture capital, networks)

Export Promotion (services to producers, expositions)

City Marketing (targeting of firms, investment incentives)

Cultural (marketing ethnic diversity, internationalism)

External Relations

(protocol, city image, international events)

Organization:

Participants-Leadership

Tasks-Responsibility

Time line

Financing-Budget

Evaluation and Update of Plan

Economic Prosperity Indicators

QoL 


\section{Phase \#3. Implementation and Evaluation}

Depending on the depth and scope of the two previous steps, some activities can begin immediately, but full implementation may take two or three years. In fact, provision should be made to update information and re-formulate the plan on a periodic basis, so that future decision-making is made on the basis of up-to-date information.

Provision for objectively evaluating each component of the plan, utilizing traditional and non-traditional indicators of economic prosperity and QoL, should be built into the plan from the outset.

It is clear that involving people who have an economic stake in the city's future can improve chances for the plan's success. This usually means involving those enterprises that are the least mobile, like labor unions and professional associations, public utilities (energy, transportation and communications), locally-owned media and business services firms (law and accounting firms, banks, freight forwarders).

Last, but not least, the endeavor should involve local universities which can provide specialized expertise on a wide range of topics, from science and technology, to urban planning and international business strategy. Advanced students can also be utilized as staff-interns helping to organize the various committees and task forces that will be formed. ${ }^{14}$

\section{APPLICATIONS TO THE SAN DIEGO-TIJUANA REGION}

The cities with the greatest economic potential in the 1990's will be those which possess a diverse economic base, qualified human capital, strong local linkages with knowledge-based institutions, a high quality of life, modem tele-communications and transport links, and the institutional capacity to develop and implement future-oriented development strategies (Commission of the European Communities, 1992:22).

The major issue now confronting San Diego is the recession itself: how to replace the thousands of relatively high-paying jobs that have been lost over the last three years, and end the downward economic spiral. All other issues (i.e., military-civilian conversion, the North American Free Trade Agreement (NAFTA), pressing transportation infrastructure needs, the real estate-construction-financial crisis, etc.) are either derived from, or secondary to, this central issue. However, as already pointed out in the

14 Clearly not all universities, nor all faculty, are open to this type of partnership; however, budget cuts and downsizing have impacted academia as well as business and government, forcing structural changes there as well. There is a great deal of discussion as to the new role of the university in this new environment. 
introduction of this paper, this "crisis" is the product of a convergence of long-term structural and short-term cyclical forces that are not likely to change dramatically in the short term. It must be recognized that

"any reference to a normal recovery - in the sense that the economy will soon resume its expansion at historic growth rates- is simply inappropriate now. San Diego's post-World War II economic growth machine was built mainly on military-related, federal government expenditures, rapid population growth, and land-based development. The growth machine simply has expired". (Clement and Zepeda, 1993b).

\section{Toward a City Strategy}

In response, a number of efforts already have been initiated to "restructure" San Diego (and Tijuana), including:

- A San Diego Intemational Trade Center (now underway under the leadership of the City of San Diego).

- Military-civilian conversion projects (now underway under the leadership of the City of San Diego).

- On-going consultation and coordination on planning between the City of San Diego and the Municipality of Tijuana.

- An on-going dialogue between the San Diego and Tijuana business communities (now underway under the leadership of the Greater San Diego Chamber of Commerce).

- An effort to consolidate certain governmental functions by the City and County (e.g., border/international affairs).

- A joint effort by the Greater San Diego Chamber of Commerce and San Diego Dialogue, to develop transportation and infrastructure mechanisms, and exploit transborder "industrial complementaries" in the San Diego-Baja Califomia region.

- Studies by the San Diego Association of Governments (SANDAG) suggesting policies to enhance economic prosperity and $\mathrm{QoL}$.

- A joint study of the current crises in San Diego and Tijuana (by SDSU and COLEF).

- A joint project (headed up by SDGE and SDSU with the City of San Diego, SANDAG, and Baja California participation) to create economic models of the Baja California-Southem Califomia region.

- An effort to consolidate the many attempts to measure QoL in the San Diego region (by the Mayor's office).

- Two studies (by the City of Tijuana and the State of Baja California) to analyze the competitiveness of the two entities, studies which in turn will be used to formulate strategic economic plans for the region. 
All of these efforts are valuable, and reflect hundreds of hours of study and deliberation by groups of concerned people who, in many cases, have never worked together. At some point, however, these efforts need to be brought together, so that a coordinated city strategy can emerge. This, however, will require strong leadership that is prepared to:

1) Make a long term commitment to building a diversified economic base as well as "a city that works" (enhanced QoL); what some people now call "sustainable development",

2) Develop consistent, coordinated economic and infrastructure policies as well as a strategy for "city marketing", based on solid economic analysis and collaboration between business, labor, government and academia, and

3) Overcome the fragmentation of planning and implementation activities that has characterized San Diego's governmental structure throughout this century (Sparrow and Walshok, 1993).

Like other cities that have successfully responded to the new conditions, San Diego must identify and build on its strengths, and correct its weaknesses in order to maximize its competitiveness. In virtually all cities visited by the author, an economic vision or strategy statement (e.g., "Calgary 2020", "An Economic Strategy for Vancouver in the 1980's") was generated by business, labor, government and academic leaders in a process that required them to organize and analyze data, hear different viewpoints and make difficult decisions regarding the region's future. While such an exercise is subject to many political and interest group pressures, it does focus attention on the region's problems, and on the need for the major economic and political actors to work together. However, the process itself does not insure that the resulting plan will be a consistent or effective one; that condition must be imposed by staff, and the leadership itself, just as in a private corporation. ${ }^{15}$

\footnotetext{
15 According to Rumelt (1980), a good business strategy must have the following characteristics:

1. consistency: it must present mutually consistent goals and strategies,

2. consonance: it must represent an adaptive response to the external environment and to the major changes occurring within it.

3. advantage: it must provide for some type of competitive advantage in the selected area(s) of operation, and

4. Reasibility: it must be feasible in terms of the organization's existing or readily attainable skills and resources.

These criteria could be used to evaluate a city strategy. Recent disregard for "vision" and long term "strategic planning", which emphasizes pure cost cutting (see "Robert Eaton Thinks 'Vision' Is Overrated and He's Not Alone", Wall Street Joumal, October 4, 1993), may be short sighted by ignoring other elements contributing to the long-term success of firms and/or cities.
} 


\section{San Diego-Tijuana Relations}

The main question for San Diego is not whether a comprehensive planning exercise should or should not be carried out, but should it be done in collaboration with Tijuana. The answer depends on one's view of the kind of relationship that the two cities should have in the future.

One view is that San Diego and Tijuana will have quite independent development paths in the future, and therefore should collaborate only to the extent necessary to keep out of each others' way, and facilitate, through the provision of infrastructure, normal intercourse between neighboring cities. This we might call the "peaceful coexistence" option. The other, however, holds that the two cities' development paths are quite interdependent, and that the two cities must develop a close "partnership" by forging a joint vision of the future of the region and a plan for achieving it. ${ }^{16}$ The "Euroregions" of the EC might provide models of this type of relationship; however, the best model might be found much closer to home in the Vancouver-Seattle region. (British Columbia Round Table on the Environment and the Economy, 1993).

\section{San Diego's Role in the Global Economy}

What is, or what could be San Diego's function(s) in the global or Western Hemispheric economy? Some years ago local leaders were referring to San Diego yearningly as a new Hong Kong, suggesting that it could become an entrepot where goods and services arrive in San Diego for warehousing, processing and transhipment to/from Mexico, Latin America and Asia. As suggested above, this refers to San Diego as a "gateway city".

The problem is that San Diego's location and historical development have not favored this type of development. While many regional firms now provide a variety of service in these sectors, and will continue to do so in the future, San Diego's position in the regional transportation infrastructure is hardly up to attaining major "bridge city" status between the U.S., Mexico, Canada and the Pacific Rim. And, despite the fact that World Trade magazine's list of the "Top 10 Cities for Global Companies" included San Diego (October, 1993), few international firms have chosen

\footnotetext{
${ }^{16}$ Irrespective of one's view regarding a trans-border economic development polity, it is clear that close collaboration is essential in order to solve the many environmental and health problems that "spill over": the border, and to take advantage of the potential economies of scale that can be realized by avoiding duplication in the construction and maintenance of major infrastructure projects such as an regional airport or sewage treatment facilities.
} 
to locate their headquarters here, disqualifying it as a major "point of access city", at least in the near future. In fact, by most criteria it must be admitted that San Diego is a long way from being, or even becoming, a major "international city" of any sort (Fry, Radebaugh and Soldators, 1989; Kresl, 1992; DATAR, 1989).

In this context, San Diego's major economic function could very well be "the city in between Los Angeles and Baja California." That is, not only may Los Angeles be one of San Diego's most important direct trading partners, but also one of the largest participants in Baja's "maquiladora" (assembly-manufacturing) industry, the industry that has contributed the most to the internationalization of the San Diego-Tijuana region. Not only have Southern Califomia firms flocked to Baja (Clement and Jenner, 1987), but many Asian firms have located there as well. As a consequence, the transborder region has attracted a growing number of small, internationally-oriented, business service firms, ranging from maquiladora shelter operators, sub-contractors and general consultants, to law, accounting and freight-forwarding firms specializing in transborder business. The experience and knowledge gained in this context have given these firms the expertise to take client international firms to other countries in Latin America.

If this link between Mexican, U.S., Asian, and other firms can actually be transmitted to other regions on a significant scale, San Diego-Tijuana could be emerging as another type of entrepot, an "information entrepot" ${ }^{17}$ This role, not incidentally, is reinforced by the fact that the largest concentration of U.S.-Mexican-Latin American research institutions in the world is located in the region. These institutions already have a long track record of developing collaborative relations with colleagues in Mexico at the transborder regional, national and hemispheric levels. Additionally, San Diego's emerging position as a technological "hot spot" (Business Week, October 19, 1992), could be enhanced by increasing the applications of these technologies and expertise to other geographical areas. ${ }^{18}$

Finally, the expertise concentrated in an "information entrepot" could be helpful in facilitating the transborder, industrial complementarities that

\footnotetext{
17 This type of hypothesis is testable, and could be determined by surveying firms involved directly and indirectly. Such a survey could also be utilized to determine what kinds of policies could be introduced to attract other firms to this "cluster".

18 The development of targeted industries for attraction to and expansion in the San Diego region is more complex than commnonly recognized. For a survey of efforts to understand this issue in the San Diego context, see Singh's appendix, "San Diego, Job-Base Studies" in Clement and Zepeda, (1993).
} 
potentially exist in the region. Firms interested in Tijuana's "manufacturing environment" next door to San Diego's technology development capabilities, could be attracted/retrained by this alluring combination. (Binational Task Force on Economic Development and Transportation Infrastructure, 1993).

\section{Urban Networking on the U.S.-Mexican Border}

Assuming that San Diego (with Tijuana?) is quietly becoming an "information entrepot" by exporting its border experience to other areas of the Western Hemisphere, how might public policy foster this function?

First, it is clear that the concept of San Diego as an "information entrepot" must be better understood. Which sectors of the economy are now engaged in this type of activity, and which sectors could be in the future? Are special incentives needed to foment their development? Are there skills that could be taught locally, in order to foster this competitive advantage?

Second, academia's potential contribution to, and relation with, business and government, needs to be clarified and utilized much more extensively. While basic research in the development of bio-tech and communications has received a great deal of attention, there are many business and governmental functions that could be enhanced by closer collaboration with regional universities, from the expanded use of student interns, to the sharing of faculty/practitioner expertise through a public-private-academic partnership.

One specific area which could be expanded in this context to reinforce the concept of the "information entrepot", is the development of an electronic network linking academic, government and business providers and users of data related to the region's development on both sides of the border. This concept, introduced originally by the City and County of San Diego in collaboration with SDSU, is now moving forward as a pilot project. Eventually the network could be expanded conceptually from "regional development" categories to "cross-border cooperation", and geographically to include other "twin cities" on the U.S.-Mexican and U.S.-Canadian borders, as well as borders in Europe. ${ }^{19}$

\footnotetext{
19 SDSU has recently received a grant from the U.S.Information Agency to collaborate with COLEF and the University of Calgary in Alberta, Canada, to develop regional development programs in the context of North American integration. Additionally, several SDSu border experts have already begun to study cross-border cooperation and conflict in many other countries.
} 
The basic concept involved in "electronic networks", is that frequently information and experience already exist regarding a new or novel idea that a government agency or private firm would like to develop. The problem is how to find that study or data set, that will help to solve the particular problem at hand. By getting users and providers "talking together" electronically, and by providing data clearing houses, the use of information can be expanded, resulting in increased efficiency. Small and medium- size firms, which now create most of the hew jobs, are also most likely to utilize these networks, as their small scale does not permit them to carry out their own "research" in these areas.

These concepts suggest a third, related concept that could be utilized to increase San Diego's international visibility, and thereby enhance its (potential) position as an "information entrepot". Just as Strasbourg (France) has positioned itself to "further cooperation and transfer of know-how and technology between EC towns and their counterparts in Eastern and Central Europe" (Trautman, 1992), so could San Diego (and Tijuana?) position itself to play this role as the "bridge" between North and South America. ${ }^{20}$ The idea is not all that far-fetched, nor would it require an enormous amount of resources. As North American economic integration proceeds, the need for hemispheric programs of this type will grow.

\section{Economic analysis}

When the subject of economic analysis is interjected into discussions of regional development, most people's eyes glaze over, an awkward silence emerges, and the subject is quickly changed. While economic data and models certainly have their limitations, when properly understood and utilized, they can be utilized for analyzing regional economic relationships and competitiveness, as well as estimating the economic (e.g., jobs and incomes) and environmental (e.g., air pollution and water) requirements of actual and potential changes in a region's economy. As such, they can be utilized by both private and public sector entities for planning and project evaluation. While San Diego already has a number of economic models (e.g., SANDAG \& SDGE), none of them explicitly analyzes the region in relation to Baja California or Los Angeles.

\footnotetext{
${ }^{20}$ This concept was suggested by Dr. Hans Brinner, ex-director of the "Regio Basiliensis", in Basle, Switzerland. Dr. Brinner has visited San Diego several times over the last decade, and has long advocated the importance of comparative border studies and experience exchange in border cooperation.
} 
As noted above, a project has been initiated to fill this void, and within two years computerized economic models of Baja Califomia and the entire Southern California region will be available to analyze the region's economic development issues and strategies.

Of course, this does not insure that decision makers will utilize these models; however, the decision makers should be aware that many of the region's principal competitors (e.g., Los Angeles and Arizona) are already utilizing such models in the formulation of their plans.

\section{Quality of Life}

The "new paradigm" outlined in the first section of this paper clearly maintains that QoL is an important, if not the most important, factor in determining the location of the high value-added firms. What is important, is that San Diego's unique climate, beauty and location are now more important than ever in this increasingly globalized world, where the importance of economic borders is rapidly diminishing. It has been argued elsewhere (Calavita, 1993) that San Diego currently does not have an adequate system for measuring QoL. Given the importance of this factor in the region's development, this deficiency should be addressed in the near future.

\section{Strategic City Networking}

Most cities have "sister city" relationships, and are members of city associations for lobbying and for sharing expertise and information. The "new paradigm" outlined above clearly indicates that cities must accept more responsibility for their own economic development, and must internationalize their operations if they are to thrive in the new environment. When properly conceived, however, internationalization is simply one component of the overall development thrust.

The "domestic" component of a development strategy requires strategies that insure that the city-region "works", in that it is an efficient and pleasant place to work and live. The "external" component, however, requires strategies that not only project the virtues of the region to the rest of the world ("city marketing"), but also must provide links that strategically position the region's firms to better acquire the best available production and distribution advantages, and to connect local government with counterpart entities that are struggling with similar issues of economic and social development. In this context, formal and informal relationships gain importance and must be viewed strategically, 
Again, space prohibits lengthy discussion of this rather complicated topic. However, there is little doubt that most large cities today see "international affairs" (i.e., trade offices in other countries, visitor and protocol offices, international missions, and sister-city programs) as mechanisms for "strategic networking" designed to strengthen the region's economic linkages. Just how this is done, however, depends on the resources and competitive position of each city-region (Soldatos, 1991).

San Diego's position as a major "border city" - "o close to Mexico, so far from Washington"- has always been a problem. This suggests that a revival of the "League of Border Cities and Counties", which existed in the 1970 's might be appropriate in order to remind the nations' lawmakers of the border region's unique needs. Additionally, a sister-city relationship with Basle, Switzerland, or a sister "twin-city" relationship between San Diego-Tijuana and Seattle-Vancouver could be advantageous. Similarly, San Diego's position as a technological "hot spot" provides it affinity with many other city-regions in North America. Obviously, these activities have costs, but they can also yield benefits. In the longer term, thoroughly rethinking the region's current constellation of international relationships in terms of their strategic value could be enormously helpful.

\section{Table 6. Main Elements of a Coordinated/Comprehensive Strategy for Economic and Infrastructure Development in San Diego.}

1. Define and develop a "working relationship" between San Diego and Tijuana: ("minimal coexistence" or "partnership"?).

2. Define the region's role in the global \& hemispheric economy ("A North American Information Entrepot"?) and develop a plan to enhance that role.

3. Use economic research to assess the region's competitiveness, and develop an "economic map" of the region's economic linkages, and to formulate infrastructure and city marketing plans.

4. Establish a reliable approach for evaluating QoL: "a city that works" for both business and people ("sustainable development").

5. Organize the region's international affairs to enhance economic competitiveness (strategic city networking). 


\section{SUMMARY AND CONCLUSIONS}

The global economy is changing rapidly, and San Diego's current crisis is in part due to these changes. Additionally, the region's past economic development depended heavily on military and military-related expenditures, which are now being reduced. Thus, local decision-makers are now being forced to change their thinking and their policies to take into account the changes in technology and economic structures that simultaneously bring hardship and new opportunities for cities previously condemned to the periphery.

The major thesis of this paper is that, based on the experience of other North American and European city-regions, San Diego is well positioned to take advantages of structural changes now occurring in the global economy and, in the long term, can enhance both its economic prosperity and quality of life. The author's study suggests four areas where further efforts are needed to facilitate progress toward these ends.

1. The development-implementation of a comprehensive strategy for economic and infrastructure development. "San Diego 2020", or something similar. Ideally, such strategies should come out of an evolving partnership between business, labor, government and academia, and use economic analysis to determine the region's competitiveness in regional, national and international markets, and to analyze the economic impact of proposed infrastructure projects and other policy proposals.

2 . The development of a working relationship between San Diego and Tijuana, based on mutual understanding, self-interest and knowledge of changing global conditions, in order to formulate a long-term regional strategy. Such a relationship can range from "peaceful coexistence" to "partners in development".

3. The development of a comprehensive approach to measuring and continually monitoring QoL in the region. Efforts to enhance the region's economic prosperity must take into account that a high quality of life $(\mathrm{QOL})$ -a "city that works for both business and its people"-is, arguably, the most important factor in attracting and retaining high value-added manufacturing and service firms.

4. The development of a strategy to enhance the region's role in the global economy. On the strengths of its existing international firms, emerging high-tech sectors and academic institutions, as well as its unique climate and location, San Diego-Tijuana may be becoming a North American "information entrepot", In this regard, San Diego must not only restructure its domestic policies, but rethink its international affairs in terms of "strategic networking" within the overall city-region strategy. 
Clearly, progress is being made in all these areas, and the process of restructuring is now in motion. Nevertheless, this process is far from complete, and in the context of the current deep and prolonged crisis, it will take many years to implement and refine.

\section{REFERENCES}

ATALIK, B. 1990. "Some Effects of Regional Differentiation on Integration in the European Community", Papers of the Regional Science Association, Vol. 69.

AYDALOT, Philippe and David Keedle (eds). 1988. High Technology Industry and Innovative Environments, London: Routledge.

Binational Task Force on Economic Development and Transportation Infrastructure. 1993. "Planning for Prosperity in the San Diego/Baja California Region", San Diego, Greater San Diego Chamber of Commerce and the San Diego Dialogue.

British Columbia Round Table on the Environment and the Economy, 1993. "Georgia Basin Initiative: Creating A Sustainable Future". Vancouver.

CALAVITA, N. 1993. "Measuring 'Quality of Life' in San Diego" in Clement, N. \& Zepeda, E., eds. (1993) San Diego-Tijuana in Transition. San Diego, Institute for Regional Studies of the Californias, San Diego State University.

CLEMENT, N. \& Jenner, S. 1987. "Location Decisions Regarding Maquiladora/In-Bond Plants Operating in Baja California, Mexico". Border Issues Series 3, Institute for Regional Studies of the Californias, San Diego State University.

CLEMENT, N. \& Zepeda, E., eds. 1993a. "Linked Destiny: Border Cities In Transition as OId Engines of Growth Stall". The San Diego UnionTribune, June 27.

- 1993b, San Diego-Tijuana in Transition. San Diego, Institute for Regional Studies of the Californias, San Diego State University.

Commission of the European Communities: Directorate-General for Regional Policy. 1991. Europe 2000: Outlook For The Development Of The Community's Territory. Brussels.

- 1992. Regional Development Studies: Urbanization and the function of cities in the European Community. Brussels.

DATAR (Delegation al' Amenagement du Territoire et al'Action Regionale). 1989. Les Villes Europeennes. Paris: La Documentation Francaise. Ekistics: The Problems and Science of Human Settlements (Double Issue) 
(1991-2), Urban Networking in Europe - I \& II. Athens, Greece, Athens Center of Ekistics of the Athens Technological Organization. FRY, E., Radebaugh, L., Soldators, P., (eds.) 1989. The New International Cities Era: The Global Activities of North American Municipal Governments, Provo, Brigham Young University.

GANSTER, P. 1993. "Transborder Linkages in the San Diego-Tijuana Region" in Clement, N. \& Zepeda, E., (eds.) 1993. San Diego-Tijuana in Transition. San Diego, Institute for Regional Studies of the Californias, San Diego State University.

GARNICK, D. 1990. "Accounting for Regional Differences in Per Capita Personal Income Growth: An Update and Extension". Survey of Current Business, Vol. 70.

GERBER, J., "Cycles and Trends in San Diego and Califomia", in Clement, N. \& Zepeda, E., (eds.) 1993. San Diego-Tijuana in Transition. San Diego, Institute for Regional Studies of the Californias, San Diego State University.

GLICKMAN N. \& Woodward, D. 1989. The New Competitors. New York: Basic Books.

KRESL, P. 1991. "Gateway cities: A comparison of North America with the European Community", Ekistics, Vol. 59 (special issue on "Urban networking in Europe - I"),

- 1992. The Urban Economy and Regional Trade Liberalization. New York: Praeger.

MARTINOS, H. \& Caspara, A. 1990. Cooperation Between Border Regions For Local and Regional Development. Brussels: Commission of the European Communities, Directorate-General XVI.

NUKAMP, P. 1990. "Spatial Developments in the United States of Europe: Glorious Victories or Ignominous Defeats?". Papers of the Regional Science Association, Vol. 69.

REGIO Basiliensis. 1988. "Region Report: 1963-2013". Basle, Switzerland.

REICH, R. 1990. The Work of Nations. New York: Vintage Books.

San Diego Association of Governments (SANDAG). 1992. Evaluating Economic Prosperity in the San Diego Region. San Diego.

San Diego Association of Governments (SANDAG). 1993. Regional Economic Prosperity Strategy. San Diego.

SINGH, H. 1993. "San Diego, Job-Base Studies" in Clement, N. \& Zepeda, E. (eds.). 1993. San Diego-Tijuana in Transition. San Diego, Institute for Regional Studies of the Californias, San Diego State University. 
SOLDATOS, P. 1991. "Strategic Cities Alliance: an Added Value to the Innovative Making of an International City", Ekistics, Vol. 59 (special issue on "Urban networking in Europe--I").

TRAUTMAN, C. 1992. "Strasbourg and the ECOS program for the cities of Central and Eastern Europe". Ekistics, Vol. 59 (special issue on "Urban networking in Europe -- II"). 